\title{
The Olive Fruit Wine Research on the Fermentation Process and Aromatic Ingredients
}

\author{
Jitian Song ${ }^{1, a}$, Xi Chen ${ }^{1}$, Yuchen Song ${ }^{1}$, Wei Tian ${ }^{1}$, Jianbo Liu ${ }^{1}$ \\ ${ }^{1}$ College of Mechanical Engineering, Tianjin University of Science and Technology, Tianjin China \\ aemail: songjt@tust.edu.cn
}

Key words: Olive wine; Fermentation; Aromatic Ingredients; GC-MS

\begin{abstract}
In order to obtain the olive wine that has pure taste, rich in nutrient. This paper uses the olive juice, olive pomace, and the mixture as fermentation materials. As a result, three different olive wines are obtained. The components in wine are analyzed by GC-MS. The results show that the olive wine made by the mixture has the most aromatic ingredients. The aromatic ingredients in olive pomace wine are the smallest.
\end{abstract}

\section{Introduction}

Olives, also known as Chinese olive, is the southern subtropical fruit trees. Olive fruits have the remarkable effects in clearing away heat and toxic material, helping produce saliva and slake thirst, being hepatoprotive and anti-alcoholic and being anti-hepatitis B virus, etc. Olives also have the effect in improving the liver detoxification function by directly eating ${ }^{[1]}$. Moreover, it is recorded that olives have effects in relaxing the muscles and stimulating blood circulation, dispelling rheumatism, and medical treatment and acid hemp, enteritis diarrhea in the compendium of material medical ${ }^{[2]}$. It is listed as one of China's first batch of "medicine and food resources" in $1979^{[3]}$.

It's rich in nutrients of olives, containing $1.1 \%$ fat , $4.1 \%$ coarse fiber, $1.4 \%$ ash content, $6.1 \%$ sugar, and $1.7 \%$ protein $^{[4]}$. Currently, there are only few products, such as olive preserves, olive tea, and olive wine. The detailed study of olive wine products is still rare and previous studies focus on the process, largely depending on experience. There is no specific theory and the corresponding data support. Therefore, it is necessary to study the process of olive wine in detail.

\section{Experimental equipment and materials}

The experimental equipment includes glass distillation bottle;stainless stell fermenter;cylinder; juice extractor;digital display thermometer;refractometer;double-deck stainless steel steamer;Gas chromatograph-mass spectrometer (GC-MS);65 $\mu$ m extraction head; water bath.

The experimental materials includes olives; $\mathrm{NaOH}$ reagant;pectase;cellulase; fruit and vegetable cleaning agent; white suger; angel high active dry yeast.

\section{Experimental method}

\section{Olive pretreatment}

Firstly, we select full of fresh olives with no plant diseases and insect pests and then use clean water to wash them and remove surface dirt. Then put the cleaned olive fruits into $1.0 \% \mathrm{NaOH}$ solution for 21 hours in order to remove the bitterness of the olive ${ }^{[5]}$. The following step is to put the olives in $70{ }^{\circ} \mathrm{C}$ of hot water about $8 \sim 10 \mathrm{~min}$ in order to soften olive group and be convenient to nuclear. After the completion of the heating, we use the artificial method to nuclear olive stone. So we can deal them with being nucleated, just left olive pulp with centrifugal juicer, make juice. We finish the olive pretreatment in the end.

\section{Olive wine fermentation}

\section{Olive wine fermentation pretreatment}

There are three different raw materials in olive wine fermentation. The first ingredient is mixture 
of olive fruit and pomace; the second is olive fruit juice; the last is olive pomace.

The mixed fermentation way is to well blend with the broken olive pomace and fruit, then put three times of the mass of water into the mixture, then stir well. To add a certain amount of enzyme into the mixture, the yield of olive juices will be rising with the increasing enzyme concentration. The yield can reach up to the maximum by the concentration $0.010 \%$, when the enzyme concentration within the scope of $0.001 \% \sim 0.010 \%{ }^{[6]}$. It can produce lots of heat in the process of enzyme solution for the mixture, so it needs to constantly stirring in order to prevent the temperature too high. It should stop stirring in order to influence the enzyme activity when the temperature will be up to $30{ }^{\circ} \mathrm{C}$, because the enzyme solution was basically completed. After the completion of enzyme solution, we should filter the mixture to remove insoluble solids.

It needs complex water activation before yeast inoculation. The first step is to add the dry yeast to the water at the temperature of $35{ }^{\circ} \mathrm{C}$ and its dosage is six times weight of the dried yeast by insulation with $25 \mathrm{~min}$. The following step is to add the yeast of completed activation to the fermentation liquor, its dosage is $100 \mathrm{~L}$ fermentation liquor within $20 \mathrm{~g}$ dried yeast in order to guarantee that $1 \mathrm{ml}$ juice contains $10^{6}$ active yeast calls ${ }^{[7]}$.

The fermentation method for olive juice is just to use its juice for fermentation by adding three times water into the juice, without adding cellulose and pectinase, then use the above method to yeast inoculation. The olive pomace fermentation is just to use pure olive pomace for fermentation by adding add three times water into the pomace, and then use the above method to add cellulose and pectinase, and complete the yeast inoculation.

\section{Olive wine fermentation process}

Firstly, we need carbohydrate supplement maintain the sugar between 12 14 Brix. After the completion of fermenting liquid by carbohydrate supplement, it should put the shade environment and ensure that the $\mathrm{CO}_{2}$ would be able to discharge out, and the air cannot enter the fermentation tank in the fermentation process, so it can provide the anaerobic fermentation environment. In addition, in order to avoid fermented liquid too much contact with outside air to the oxidation to make olive brandy becomes flat. It has to make the fermentation tank sealing strong.

In the experimental process, we record the olive fermentation medium acidity, temperature, Brix in the change of the physical and chemical indicators every 12 hours. It could stop fermentation when the index as the above mentioned no longer changed.

\section{Olive yeast components testing}

After the end of the fermentation, the GC-MS is used to detect the aromatic in the olive brandy successively to analyze the fresh olive juice, olive pomace, olive juice fermented liquid, olive pomace fermented liquid, and the mixed fermented liquid of the aromatic component. In the process, each sampling is $5 \mathrm{ml}$ in the water bath pot heating $30 \mathrm{~min}$ and keeping the water bath temperature $55{ }^{\circ} \mathrm{C}$. After the completed of water bath, using the $65 \mu \mathrm{m}$ extracting head is to extract sample for 30 $\mathrm{min}$, and put sample $15 \mathrm{~min}$ into GC-MS. Each sample should analyze for $50 \mathrm{~min}$.

\section{Experiment data analysis and discuss}

\section{Fermentation process data analysis}

This study needs to record the variation of temperature, sugar and acidity in the fermentation process of olive juice every 24 hours. To reduce the experiment error, the mixed olive juice is divided into two groups to measure the change of physical and chemical indicators. The measurement is stopped when the change of these indicators is no longer varied.

\section{The temperature variation of the fermentation process}

The fermentation temperature in the olive juice fermentation process is an important parameter, which not only affects the quality of olive wine, but also reflects the intensity of the olive fermentation process. This can provide a reference for the fermentation finishing time in the study. The external environment fermentation temperature is $16{ }^{\circ} \mathrm{C}$. The temperature variation of the olive liquid fermentation process is shown in figure 1.

Due to the olive juice containing more sugar and nutrients in the initial stage of fermentation, the yeast activity is stronger as the fermentation is acute and more heat is produced. Along with the 
fermentation, due to the yeast cell metabolism, sugar gradually consumed and yeast cell's activity decreased. Meanwhile, the fermentation strength began to abate and the heat yield began to fall. The temperature changes in three different types of fermentation as there is a downward trend at the beginning, the temperature is no longer changed at $84 \mathrm{~h}$, similar to room temperature. The fermentation process is very weak, maybe even stops, so the fermentation could be terminated at this time.

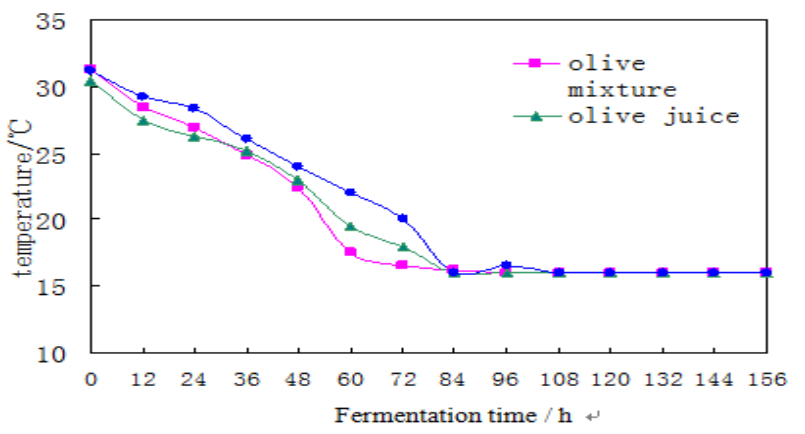

Fig. 1 The variation of temperature changes in the olive liquid fermentation process The variation acidity of the fermentation process

The fermented liquid acidity of olive wine has great influence on its quality, and the acidity is an important symbol in quality evaluation of olive wine.

At the beginning of the fermentation process, the yeast is used for both aerobic and anaerobic fermentation because of a small amount of oxygen in the initial stage in the fermentation liquid. As the oxygen gradually exhausted, the fermentation process is mainly used for the anaerobic fermentation. The process is as follows:

$$
\begin{aligned}
& \mathrm{C}_{6} \mathrm{H}_{12} \mathrm{O}_{6} \rightarrow 2 \mathrm{C}_{2} \mathrm{H}_{5} \mathrm{OH}+2 \mathrm{CO}_{2}+\text { Energy } \\
& \mathrm{C}_{6} \mathrm{H}_{12} \mathrm{O}_{6}+6 \mathrm{O}_{2} \rightarrow 6 \mathrm{H}_{2} \mathrm{O}+6 \mathrm{CO}_{2}+\text { Energy } \\
& \mathrm{C}_{6} \mathrm{H}_{12} \mathrm{O}_{6} \rightarrow 2 \mathrm{CH}_{3} \mathrm{COOH}+2 \mathrm{H}_{2} \mathrm{O}+\text { Energy }
\end{aligned}
$$

Type (1) is the anaerobic fermentation process, whereas type (2) is the aerobic fermentation process. Type (3) is a full fermentation to produce acetic acid fermentation process, so it must be controlled for a full fermentation process. The acidity variation of the olive fermentation process is shown in figure 2(a).

It can be seen that three kinds of fermented juice $\mathrm{PH}$ values have the same change trend from Figure 2(a). After a period of beginning time, the $\mathrm{PH}$ has a downward trend . The $\mathrm{PH}$ is no longer changed when the fermentation is up to $48 h$ and it keeps around 4 . This is because there are lots of acid produced in the original time within $48 h$ and the acid substances are dissolved in water. As a result, the acidity in the fermented liquid falls fast. Otherwise, yeast fermentation leads to the

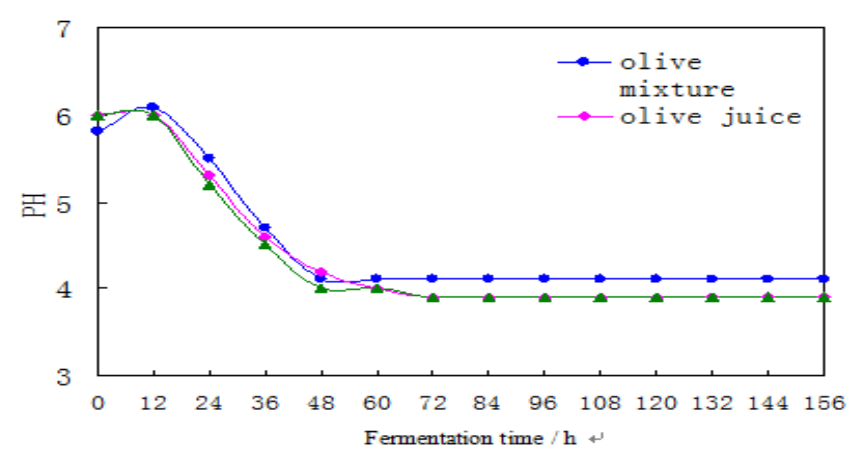

(a)acidity

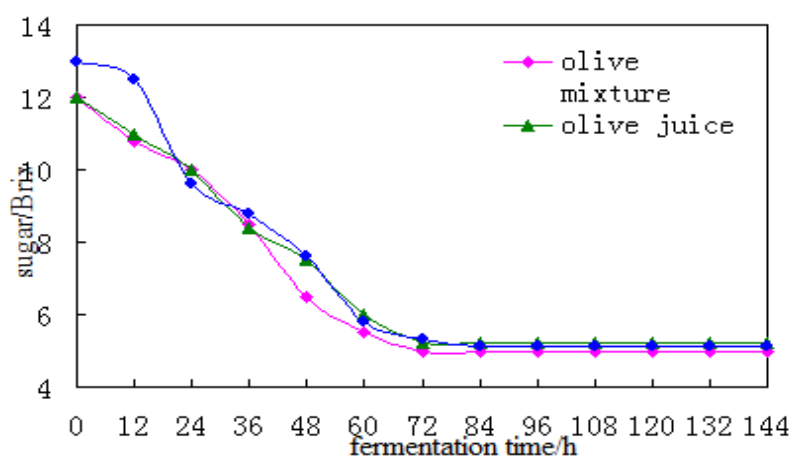

(b)sugar

Fig. 2 The variation of acidity and sugar changes in the olive liquid fermentation process production of acetic acid, which can promote the acidity of fermented liquid. There are lots of yeast cells death, which can maintain the acid at the stable state after $48 h$ when fermentation is roughly leveled off. Hence, fermentation is becoming slow after $48 h$. The PH is not changed when the time 
is $84 h$, which means the fermentation is stopped.

\section{The sugar variation of fermentation process}

The alcohol is a main source for monosaccharide olive juice. It is also one of the symbols of fermentation strength. Monosaccharide can convert to alcohol after fermentation process, so the sugar has a direct influence on the output liquor rate, which needs the appropriate sugar in the deployment of olive juice. The sugar variation of fermentation process is shown in Figure 2(b).

Within the first $72 \mathrm{~h}$ of olive juice fermentation, the olive juice sugar fell fast. This is mainly due to the yeast cells being in logarithmic phase at this stage. The yeast cells correspondingly grow rapidly. The activity is stronger, and large sugar is consumed. It can be found that the sugar shows the tendency of rapid decline. The sugar maintains a balance after $72 \mathrm{~h}$. This is because a large amount of sugar consumed by yeast cell metabolism leads to a substantial reduction in the number of yeast cells. The fermentation process is stopped at $84 \mathrm{~h}$.

\section{The aromatic component analysis for the olive fermented production}

\section{The category and content of aromatic component of the olive fermented production}

It contains a variety of aromatic components by testing the sample of olive fruits, olive juice fermented liquid, fermentation liquor of olive pomace, and the mixture of olive juice and pomace, using the GC-MS. The testing result is shown in Table 1.

There are 13 categories of materials detected in the juice and pomance, in which the most abundant substances is alkene, accounting for $79.5 \%$ and $75.8 \%$, respectively. Ester is the most abundant substances in the pomance yeast and the corresponding percentage is $49.4 \%$, followed by alcohols $(23.3 \%)$, alkene $(9.6 \%)$. The total content detected here is $92.2 \%$. However, the most abundant content is ester in the juice yeast, around $54.781 \%$, followed by alkene, $(30.377 \%)$, alcohol $(7.233 \%)$. The total content detected for the juice yeast is $92.4 \%$. Meanwhile, the most abundant is alkene $(52.0 \%)$ in the mixture yeast. For the ester and alcohol, the content is $21.1 \%$ and $9.0 \%$, respectively. The total content detected in the mixture yeast is $88.1 \%$

Tab. 1 The fragrant component category and content in the olive liquid

\begin{tabular}{|c|c|c|c|c|c|c|c|c|c|c|}
\hline \multirow[b]{2}{*}{ Name } & \multicolumn{2}{|c|}{ Pomance } & \multicolumn{2}{|c|}{ Juice } & \multicolumn{2}{|c|}{ Pomace yeast } & \multicolumn{2}{|c|}{ Juice yeast } & \multicolumn{2}{|c|}{ Mixture yeast } \\
\hline & $\begin{array}{c}\text { percentage } \\
(\%)\end{array}$ & $\begin{array}{c}\text { material } \\
\mathrm{s}\end{array}$ & $\begin{array}{c}\text { percentage } \\
(\%)\end{array}$ & $\begin{array}{c}\text { material } \\
\mathrm{s}\end{array}$ & $\begin{array}{c}\text { percentage } \\
(\%)\end{array}$ & $\begin{array}{c}\text { material } \\
\mathrm{s}\end{array}$ & $\begin{array}{c}\text { percentage } \\
(\%)\end{array}$ & $\begin{array}{c}\text { material } \\
\mathrm{s}\end{array}$ & $\begin{array}{c}\text { percentage } \\
(\%)\end{array}$ & $\begin{array}{c}\text { material } \\
\mathrm{s}\end{array}$ \\
\hline esters & 0.284 & 9 & 0.046 & 1 & 49.367 & 16 & 54.781 & 16 & 27.116 & 18 \\
\hline alcohols & 3.872 & 7 & 5.674 & 7 & 23.26 & 5 & 7.223 & 6 & 9.006 & 7 \\
\hline alkene & 79.537 & 32 & 75.821 & 28 & 19.605 & 27 & 30.377 & 27 & 51.983 & 27 \\
\hline phenolic & 2.836 & 3 & 2.233 & 2 & 0.896 & 2 & 0.992 & 2 & 0.623 & 2 \\
\hline$P$ & 0.386 & 1 & 0.37 & 1 & - & & 0.008 & 1 & 0.067 & 1 \\
\hline ketones & 0.442 & 5 & 0.654 & 4 & 0.851 & 4 & 0.485 & 3 & 0.68 & 4 \\
\hline benzene & 2.544 & 2 & 1.449 & 2 & 0.46 & 2 & 0.314 & 2 & 0.411 & 2 \\
\hline aldehyde & 0.029 & 2 & 0.021 & 1 & 0.063 & 1 & 0.031 & 1 & 0.103 & 1 \\
\hline chamomile & 0.791 & 1 & 1.31 & 1 & 2.938 & 1 & 1.022 & 1 & 1.678 & 1 \\
\hline naphthalene & 5.061 & 5 & 8.28 & 5 & 2.232 & 5 & 3.33 & 4 & 5.912 & 4 \\
\hline indene & 0.104 & 2 & 0.066 & 1 & 0.163 & 1 & 0.126 & 1 & 0.121 & 1 \\
\hline terpenoids & 4.071 & 1 & 4.076 & 1 & 0.165 & 1 & 0.932 & 1 & 2.3 & 1 \\
\hline alkanes & 0.043 & 1 & 一 & - & - & - & - & - & - & - \\
\hline acids & - & - & - & - & - & - & 0.379 & 1 & - & - \\
\hline total & 100 & 71 & 100 & 54 & 100 & 65 & 100 & 66 & 100 & 69 \\
\hline
\end{tabular}

note : "-_"not detected

As discussed as the above, we can see that there are three mainly aroma components in the fermentation process, including ester, alcohol, and alkene. However, three substances content differs in the different fermentation ways. There are 12 kinds of aromatic components in the pomance yeast and mixture yeast. The differences with pomance yeast and mixture yeast produced acid in the juice yeast. From the fermented product, we find that the ester increased most; alkene reduced obviously. It's the unique substances that the acid in the juice fermentation process, maybe because of the acidity balanced flavor ingredients in the olive pomance, which can prevent to 
produce acids composition in the fermentation process.

\section{The change of aroma components in the olive liquid fermentation process}

There are lots of materials change in the olive liquid fermentation process, which can produce many new aromatic ingredients, meanwhile lose many aromatic components. The completely lost aromatic components in the fermentation process are shown in Table 2.

Tab.2 the completely disappeared aromatic composition in the olive liquid fermentation process

\begin{tabular}{|c|c|c|}
\hline Pomance yeast & Juice yeast & Mixture yeast \\
\hline Athyl acetate & - & - \\
\hline (S)- Verbena enol & (S)- Verbena enol & (S)- Verbena enol \\
\hline 4-terpene alcohol & - & - \\
\hline $\begin{array}{c}4 \text { - methyl - } 1 \text { - isopropyl - double loop } \\
{[3.1 .0]-2 \text { - hexene }}\end{array}$ & - & $\begin{array}{c}4 \text { - methyl - } 1 \text { - isopropyl - double loop } \\
{[3.1 .0]-2 \text { - hexene }}\end{array}$ \\
\hline $\begin{array}{c}\text { (Z) - 3, } 7 \text { - dimethyl - 1,3,6 - octadecane } \\
\text { triene }\end{array}$ & - & $\begin{array}{c}\text { (Z) - 3, } 7 \text { - dimethyl - 1,3,6 - octadecane } \\
\text { triene }\end{array}$ \\
\hline $\begin{array}{c}1 \text { - methyl - } 4 \text { - }(1-\text { methyl ethyl })-2 \text { - } \\
\text { cyclohexene }\end{array}$ & - & $\begin{array}{c}1 \text { - methyl - } 4 \text { - (1 - methyl ethyl) - } 2 \text { - } \\
\text { cyclohexene }\end{array}$ \\
\hline $\begin{array}{c}1 \text { - methyl - } 4 \text { - (1 - methyl ethyl }) \text { - (1 r, } 4 \\
\text { r) - dicyclohexyl ene }\end{array}$ & - & $\begin{array}{c}1 \text { - methyl - } 4 \text { - (1 - methyl ethyl }) \text { - }(1 \mathrm{r}, 4 \\
\mathrm{r}) \text { - dicyclohexyl ene }\end{array}$ \\
\hline$\beta$ - bourbon ene & 一 & $\beta$ - bourbon ene \\
\hline 3 - methyl - 4 - isopropyl phenol & - & 3 - methyl - 4 - isopropyl phenol \\
\hline Methyl ketone of heptene & - & Methyl ketone of heptene \\
\hline Perilla aldehyde & - & Perilla aldehyde \\
\hline $\begin{array}{c}\text { 1H - 2, } 3 \text { - dihydro - } 1 \text { - methyl - open } \\
\text { loop - indene }\end{array}$ & - & $\begin{array}{c}\text { 1H - 2, } 3 \text { - dihydro - } 1 \text { - methyl - open } \\
\text { loop - indene }\end{array}$ \\
\hline $\begin{array}{c}1 \text { - vinyl - } 1 \text { - methyl - } 2 \text { - }(1-\text { methyl } \\
\text { ethyl })-4-(1-\text { a heartland of ethyl })- \\
\text { cyclohexane }\end{array}$ & - & $\begin{array}{c}1 \text { - vinyl - } 1 \text { - methyl - } 2 \text { - }(1-\text { methyl } \\
\text { ethyl })-4-(1-\text { a heartland of ethyl })- \\
\text { cyclohexane }\end{array}$ \\
\hline- & $\begin{array}{l}1,2,3,4 \text { - four, } 1,6 \text { hydrogen }-1-3 \\
\text { methyl naphthalene }\end{array}$ & $\begin{array}{c}1,2,3,4 \text { - four, } 1,6 \text { hydrogen - 1-3 methyl } \\
\text { naphthalene }\end{array}$ \\
\hline- & 2, 5 - dimethyl - 3 - vinyl - 1,4 - diallyl & - \\
\hline- & $\begin{array}{c}4 \text { - methylene - } 1 \text { - }(1-\text { methyl ethyl }) \text { - } \\
\text { double loop [3.1.0] - hexene }\end{array}$ & - \\
\hline- & $\begin{array}{l}\text { 4,6,6 - trimethyl bicyclic [3.1.1] g - } 3 \text { - } \\
\text { ene - } 2 \text { - ketone }\end{array}$ & - \\
\hline
\end{tabular}

note : "- "not detected

Tab.3 The new-appeared aromatic composition in the olive liquid fermentation process

\begin{tabular}{|c|c|c|}
\hline Juice yeast & Pomance yeast & Mixture yeast \\
\hline Isoamyl acetate & Isoamyl acetate & Isoamyl acetate \\
\hline Is ethyl caproate & Is ethyl caproate & Is ethyl caproate \\
\hline Heptanoic acid ethyl ester & - & - \\
\hline Octanoic acid ethyl ester & - & - \\
\hline Salicylic acid ethyl ester & - & Salicylic acid ethyl ester \\
\hline Phenyl ethyl acetate & - & - \\
\hline $\begin{array}{l}\text { Decanoic acid ethyl ester } \\
\text { (Z) - } 16 \text { acid methyl ester }\end{array}$ & $\begin{array}{l}\text { Decanoic acid ethyl ester } \\
\text { (Z) - } 16 \text { acid methyl ester }\end{array}$ & $\begin{array}{l}\text { Decanoic acid ethyl ester } \\
\text { (Z) - } 16 \text { acid methyl ester }\end{array}$ \\
\hline Palmitic acid ethyl ester & - & - \\
\hline Linolenic acid ethyl ester & Linolenic acid ethyl ester & - \\
\hline Linoleic acid ethyl ester & - & - \\
\hline Stearic acid ethyl ester & - & - \\
\hline $\begin{array}{l}\text { Nutmeg acid ethyl ester } \\
\text { Lauric acid ethyl ester }\end{array}$ & $\begin{array}{l}\text { Nutmeg acid ethyl ester } \\
\text { Lauric acid ethyl ester }\end{array}$ & $\begin{array}{l}\text { Nutmeg acid ethyl ester } \\
\text { Lauric acid ethyl ester }\end{array}$ \\
\hline 3 - hexene acid ethyl ester & 3 - hexene acid ethyl ester & 3 - hexene acid ethyl ester \\
\hline styrene & - & - \\
\hline 2 - hexene trans caproic acid & - & - \\
\hline- & - & $\alpha$ - terpineol \\
\hline
\end{tabular}

note : "- " not detected

There are 14 kinds of aromatic ingredients disappeared during the pomance yeast. The disappeared aromatic in the juice yeast is 5 kinds and the mixture yeast has 12 kinds. Verbena enol vanished in the three kinds of yeast. The new aromatic components in the olive fermentation 
process are shown in Table 3.

There are 17 kinds of aroma components in fermentation process of olive juice, including 15 kinds of ester material. Namely, there are more esters in the fermentation process. There are 8 kinds of aroma components produced in the pomance fermentation process in which all the produced aroma components are ester substances. There are 12 kinds of aroma components in the mixture fermentation process, containing 11 kinds of ester substances. Olive fruit juice can fully contact with yeast nutrients in the fermentation process, so it can produce many kinds of metabolite species. A special material produced in the mixed fermentation process is the $a$-terpineol.

\section{Conclusion}

The trend in the fermentation process is that the temperature and the sugar gradually decreased, whereas the acidity increased .These indicators entered into a balance for the fermentation time to $84 h$, which was the end of fermentation.

There are 73 kinds of aroma components detected in the olives in which 5 kinds of aroma components disappeared in the juice fermentation process, while 4 kinds exist in the pomance fermentation process and 12 kinds occur in the mixture fermentation process.

There are 17 kinds of aroma components produced in the juice fermentation process, including 15 kinds of esters and 8 kinds produced in the pomance fermentation process. All these aroma components are esters. 14 kinds of components are produced in the mixture fermentation process, including 11 kinds of esters.

After the completion of the fermentation, 66 kinds of aroma components occur in the juice yeast, which account for $54.781 \%$ of ester materials. 65 kinds of aroma components are in the pomance yeast in which ester materials are responsible for 49.367\%. 69 kinds of aroma components exist in the mixture yeast, around $27.116 \%$ of ester materials. Comprehensive analysis indicates that the olive juice is more suitable for brewing olive wine.

\section{Acknowledgement}

The Project Supported by the Foundation (No. 15JCTPJC60200) of Tianjin Science and Technology Correspondent.

\section{References}

[1] Rongshu Wu,Zhenyang Ge.The development and utilization of yunnan olive series products [J].Journal of Agriculture and Animal Husbandry Products Development,1996,10,13 to 15.

[2] Hetong Lin,Lian Chen,Shaojun Chen,Jiao Lin,Yunfeng zhao.Olive fruit postharvest biology research progress [J].Journal of Fujian Agriculture and Forestry University Press,2005(4):465-469.

[3]Min Fan, Liangke Song, Hao Shang. The research progress of Chinese olive [J]. Journal of Anhui Agricultural Science, 2010, 38 (34) : 19358-19360.3

[4] Zhiyong He. Olive pulp nutrition analysis [J]. Journal of Food Science and Technology, 2008, 12:224-226.

[5] Jianyun Liang, Hongchao Zhang, Yinglian Qiu. Olive wine brewing technology research [J]. Journal of Maoming College, 2010, 20 (3) : 14-16.

[6] Xiangping Zheng, Baochun Zhang, Zuli Sun et al. Brandy volatile aroma compounds of preliminary explore [J]. China Brewing, 2012, 31 (9) : 1-5.

[7] Bei Ji ,Baolan Xue, Tianzhong Liu. Apple brandy brewing technology research [J]. Journal of Anhui Agricultural Science, 2012, 40 (9) : 5326-5328. 